\title{
Types of Parenting of Fathers during Early Childhood: A Q Methodological Approach
}

\author{
Sun-Jung Park ${ }^{1}$, Eun-Young Choi ${ }^{2}$, Ga-Yeon $\mathrm{Ko}^{3}$, Bock-Soon Park ${ }^{4}$, Byung-Jun Park ${ }^{5}$ \\ ${ }^{1}$ Assistant Professor, Department of Nursing, Yeoju Institute of Technology, Yeoju; ${ }^{2}$ Associate Professor, College of Nursing, Kyungdong University, Wonju; \\ ${ }^{3}$ Associate Professor, Department of Nursing, Gangneung Yeongdong University, Gangneung; ${ }^{4}$ Assistant Professor, Department of Nursing, Gangneung \\ Yeongdong University, Gangneung; ${ }^{5}$ Assistant Professor, Department of Nursing, Daegu Health College, Daegu · Doctoral Candidate, College of Nursing, Korea \\ University, Seoul, Korea
}

Purpose: The purpose of this study was to examine types of parenting among fathers. The characteristics of parenting each type in early childhood were identified by systematically analyzing and classifying father's perceptions of parenting using the Q-methodology, which places importance on the perspective of the performer. Methods: The Q-method, which is effective for measuring individual subjectivity was used. The subjects in this study were 50 fathers with young children (2 36 months). Results: Four parenting types were identified analyzing the subjective perceptions of fathers with young children about parenting. One type was centered on character development. Another was centered on social development. A third was centered on physical health and development. The fourth was centered on building values. Conclusion: Parenting education programs should be developed based on type-specific characteristics and further research should investigate the effects of father's parenting type.

Key words: Infant; Child; Fathers; Parenting

\section{Corresponding author Byung-Jun Park \\ https://orcid.org/0000-0002-4694-5099}

Department of Nursing, Daegu Health College,

15 Youngsong-ro, Buc-gu, Daegu 41453, Korea

TEL +82-53-320-4518 FAX +82-53-320-1470

E-MAIL byungjuny00@gmail.com

Received Jun 5, 2019 Revised Jul 5, 2019 Accepted Jul 5, 2019 (a) This is an Open Access article distributed under the terms of the Creative Commons Attribution NonCommercial License (http://creativecommons.org/licenses/by-nc/4.0/) which permits unrestricted noncommercial use, distribution, and reproduction in any medium, provided the original work is properly cited.

\section{INTRODUCTION}

\section{Need for Study}

Parental attitude or behavior is a crucial environmental factors that affects children's development in many ways. Children's relationship with their parents in the early years of their lives, the parent-child relationship, in other words is the most fundamental of human relationships, and while also being fairly complicated from a psychosocial perspective [1]. The mutual interaction between parents and children is a critical variable that directly affects children's socioemotional and cognitive development, and it also has a decisive impact on building relationships with others [2]. Specifically, paternal involvement has been found to exercise an influence on young children's well-rounded development, and to provide an opportunity for fathers to discover their own new ego and thereby restructure their character, which in turn impacts the marital relationship and increases life satisfaction [3].

In the past, providing economic security for children was viewed as the primary paternal role. Currently, though, it is considered more important to be on friendly terms with one's children, and the way that fathers conceptualize their own roles is changing. They are more likely to spend time with 
their children or focus on teaching values and skills [4].

Paternal involvement is instrumental to children's gender role learning, cognitive learning, and achievement motivation, and fathers have their own specific ways of playing and interacting with their children. Indeed, the paternal role is significant both in quantity and quality [5]. The amount and quality of time that fathers dedicate to parenting may affect their children at every developmental stage [6]. In particular, in the early childhood period-between ages 1 and 3-children learn language, life habits, and values under the care and protection of their parents, at a time when they are imaginative, fun-loving, and curious about their surrounding environments [6].

As the importance of the paternal role in early childhood is emphasized, social awareness of paternal involvement is increasing, and fathers are becoming more responsible for parenting [7]. Social pressure on fathers is becoming more intense, and their families want them to get home early to play with their children or take care of them, but it is often difficult for them to leave work early because of inflexible working hours. It is necessary to pay attention to the paternal role because fathers experience conflicts between work and family and may have difficulties in paternal role adjustment [1]. In particular, special attention should be paid to paternal parenting because paternal attitudes are different from maternal attitude, meaning that children experience complementary parenting styles from their fathers and mothers [8].

Studies of paternal parenting have taken a quantitative approach to examine the parenting experience of fathers of children with a disease $[9,10]$, satisfaction with paternal roles, paternal roles, paternal behaviors in early childhood, and paternal involvement [11-13]. Studies employing qualitative approaches have investigated the parenting experiences of young fathers and the parental attitude of fathers with preschool children [14-16].

The Q-methodology, which is a research method that compensates for the shortcomings of quantitative and qualitative research, makes it possible for respondents to describe their own inner world in a more objective manner and to categorize their awareness [17]. Therefore, this method is appropriate for researching types of individual subjectivity or attitudes, which can be useful for a study focusing on the parenting experiences of fathers with young children. Furthermore, the purpose of the Q-methodology is not to "explain psychological human characteristics from the outside" but to "understand them from within". It starts with focusing on the perspective of the performer, not with the assumptions of the researcher, and it places emphasis on inner meaning for individuals rather than their individual variance [18].

Therefore, this study attempted to conduct a systematic analysis of the parenting related perceptions of fathers with young children in an effort to identify and characterize their parenting types, as careful parenting is considered to be important and the most intensive parenting is needed in early childhood. The Q-methodology, which emphasizes the perspective of the performer, was used. In addition, this study was meant to help fathers obtain a better understanding of the types of paternal parenting and the characteristics of each type. This study is expected to lay the groundwork for the development of nursing intervention programs that aim to help fathers to raise their children in a manner that facilitates their optimum growth and development.

\section{Objectives}

The purpose of this study was to examine the types of parenting behaviors of fathers with young children and to explore the characteristics of their parenting types by applying the Q-methodology, which starts by focusing on the subjective perspective of the subject. The specifics goals of the study were two-fold: 1) to categorize the subjective awareness of fathers about parenting in early childhood, and 2) to analyze the characteristics of the types of their subjective awareness.

\section{METHODS}

\section{Study Design}

The Q-method approach was used to investigate the subjective perceptions of fathers with young children about parenting behaviors.

\section{Study Sampling}

\section{1) Selection of the Q-population and Q-samples}

A Q-population is a summation of feelings or opinions that are shared in a particular culture, which is collected through methods including a literature analysis and interview.

A Q-population of the parenting behaviors of fathers with young children was selected by analyzing the literatures. Academic journals, specialized magazines, books, and newspapers related to parenting for infants and preschoolers were analyzed to select statements related to parenting behaviors for these age groups without overlapping, and then a Q-population of 160 statements was organized. In addition, in-depth interviews were conducted to gather more practical opinions on parenting behaviors. Ten selected fathers whose children were in early childhood were interviewed in depth from July 1 to 30, 2017, to organize the Q-population. They were asked to tell the researchers about their views on parenting and how 
they felt about parenting at home and at work. It took approximately 1 or 2 hour(s) to interview each of them. The interviews were carried out with their consent, and all the interviews were taped and recorded to prevent any possible omissions. The researchers extracted 80 statements through the in-depth interviews. In total, 240 statements were extracted in the two stages. Four nursing professors had an in-depth discussion to modify them and then reselected 160 of the 240 statements. The in-depth discussion was conducted among two professors specializing in pediatric nursing, one nursing professor who wrote a thesis on Q-methodology, and one professors specializing in nursing science. This led to modifications of the statements. The re-extraction process of statements led to Q-population with a sample of 160.

Four categories were selected in this way. The selected statements were read repeatedly to categorize them according to their meaning. After the data were reviewed and modified, 40 Q-samples were finally selected (Figure 1).

\section{2) Selection of the P-samples}

Several selection criteria for the P-samples were established to organize a Q-population that seemed to clearly represent parenting behaviors for young children. According to the criteria, 50 fathers who were in their 20 s to 40 s, with children between 2 and 36 months of age, were selected. Their children had been delivered at term and were at normal growth and developmental stages. Their weight and height were in the normal range, and they had no deformities, health problems or chronic diseases. As selecting P-samples from diverse perspectives is useful for Q-research [17], the selected fathers belonged to different occupational clusters. The sample included office workers, self-employed people, teachers, professors, and, others. The criteria for the P-sample in this study were chosen to form a Q-population that would be indicative of fathers' parenting behavior in early childhood. The subjects included fathers who were now on paternity leave or who took care of a child for more than 8 hours a day [2].

The subjects received an explanation about the purpose and process of the study, and they were assured that they would remain anonymous and that all the survey and interview data would be used for the purpose of the study only. This study was then conducted with their written consent.

\section{3) Classification of the Q-samples and data analysis}

According to the forced distribution principle of the Q-methodology, a distribution chart of the Q-samples was drawn up by forcibly distributing the 40 statements that were finally selected as the Q-samples. The fathers read the Q-samples and then classified them into three bundles, depending on whether they agreed, disagreed, or were neutral. After they chose the statements with which they agreed, they put in the outermost spot the statement with which they agreed the most, and then placed their second most agreed-upon statement next to it inwards. Thus, they placed the statements with which they

\begin{tabular}{|c|}
\hline Stage 1: Q-population \\
\hline $\begin{array}{l}\text { - Structured sample: Journal, books, etc (160 statements) } \\
\text { - Unstructured sample: In-depth interviews ( } 80 \text { statements) }\end{array}$ \\
\hline$\downarrow$ \\
\hline Stage 2: In-depth discussion \\
\hline $\begin{array}{l}\text { - Four nursing professors } \\
\text { - } 160 \text { statements selected }\end{array}$ \\
\hline$\downarrow$ \\
\hline Stage 3: Categorization, review, and revision \\
\hline $\begin{array}{l}\text { - Four nursing professors } \\
\text { - } 40 \text { statements }\end{array}$ \\
\hline$\downarrow$ \\
\hline Stage 4: Pilot test \\
\hline $\begin{array}{l}\text { - } 10 \text { fathers with children in early childhood } \\
\text { - Q-sampling ( } 40 \text { statements) }\end{array}$ \\
\hline
\end{tabular}

Figure 1. The process of Q-sampling. 
agreed from outside to inside according to their degree of agreement, and finally placed the statements about which they were neutral in the neutral spot. They were specifically asked to comment on the two most extreme statements on each $(+4$, -4) [17].

After they finished placing the statements with which they disagreed, they arranged the statements with which they disagreed in the same way, beginning with the one that they disagreed with the most and then proceeding to the one that they disagreed with the least. Finally, they placed the statements about which they were neutral in the neutral spot. To improve the interpretation of the Q-factors, they were interviewed to determine why they chose the four statements $(+4,-4)$ that were in the two most extreme locations on each ends, and the reasons were recorded [19].

Additionally, they were asked to indicate their age, occupation, academic credentials, religion, living standard, form of family, number of children, and children's age and health status on the questionnaires to enable an analysis of the sociodemographic characteristics of the P-samples. The Quanl PC program was used for data analysis, and principal component analysis was carried out to analyze the $\mathrm{Q}$-factors. To produce the best results, the analysis was made by inputting all the factors with an eigen-value above 1.0, and the results of the analysis and total explanatory capability were both taken into account to make the best choice of paternal parenting types. In addition, Z-scores were used to select appropriate items [19].

\section{Ethical Considerations}

This study was implemented with the approval of the $\mathrm{K}$ University Institutional Research Board (IRB No. $K^{* * *} 2015-$ 03-003-***) to ensure research ethics. It was stated that the data would be used anonymously to protect the rights of the participants, and information on the purpose and process of the study was provided to obtain written consent. The subjects were informed that they could stop participating at any time if they wanted. It was mentioned on the first page of the questionnaire that their answer sheets would be used for the purpose of the study only, and that their personal information would not be released. Only fathers who agreed participated in this study.

\section{RESULTS}

\section{Formation of the Q-Types}

Through the Q-factor analysis using Quanl PC, fathers' subjective perceptions of parenting classified into four types. The four types explained $47.0 \%$ of the total variance, with the following breakdown: type 1, 23.8\%; type 2, 13.1\%; type 3, $5.1 \%$; and type $4,4.9 \%$ (Table 1 ). The correlations of the types are shown in Table 2.

\section{Characteristics of the Types}

Out of the subjects, 16 fathers belonged to type 1,15 to type 2,11 to type 3 , and 8 to type 4 . The demographic characteristics and factor weights are described in Table 1 . In each type, the fathers whose factor weight was higher were more typical of the type (Table 1). The characteristics of the types were described based on the statements with items about which the fathers agreed (Z-score, +2 or more) and disagreed (Z-score, -2 or more). When describing the characteristics of each type, special focus was placed on the items for which there were large disparities between the standard score for one specific type and the mean standard score for another type. The Qstatements and Z-scores $( \pm 1.0)$ for each type are shown in Table 3.

\section{1) Type 1: Centered on character development}

Sixteen of the 50 fathers belonged to Type 1 . Their average age was 40.1 years, and their children's average age was 18.7 months. Ten were university graduates and six had graduate degrees. By occupation, office workers made up the largest proportion (six fathers). Five were school members, two each were teachers and professionals, and one was a researcher. Their children (10 boys and six girls) were all in good health. The items that the fathers belonging to type 1 agreed with the most were "getting children to build the right values $(Z=2.1)$ " and "helping children to build character $(Z=1.9)$ ". Meanwhile, the items that this group disagreed with the most were "helping children to maintain personal hygiene $(Z=-1.8)$ " and "helping children acquire gender roles $(Z=-1.8)$ ". The items with which fathers belonging to type 1 strongly agreed to the extent that there was a difference of +2.00 or more between their standard scores and those of the fathers belonging type 2, were "understanding children's minds and behaviors $(Z=0.4)$ " and "helping children to build character $(Z=1.9)$ ". The items with which type 2 group strongly disagreed, to the extent that there was a difference of -2.00 or more between their standard scores and those of the fathers belonging to type 2, were "providing outdoor activities $(Z=-1.3)$ " and "helping children grow to be physically healthy $(Z=-0.2)$ ". The items with which the fathers belonging to type 1 strongly agreed, to the extent that there was a difference of +1.00 or more between their standard scores and those of the fathers belonging to type 3 , were "helping children grow into full-fledged members of society $(Z=1.7)$ " and "helping children to do what they want $(Z=0.2)$ ". The items with which the fathers belonging to type 1 
Table 1. Types, Eigen Values, Variance, Cumulative, Factor Weight, and Demographic Characteristics for P-sample

$(N=50)$

\begin{tabular}{|c|c|c|c|c|c|c|c|c|}
\hline Type & $\begin{array}{l}\text { Eigen values } \\
\text { Variance (\%) } \\
\text { Cumulative }\end{array}$ & $\begin{array}{c}\mathrm{P} \\
\text { No. }\end{array}$ & $\begin{array}{c}\text { Factor } \\
\text { weight }\end{array}$ & $\begin{array}{l}\text { Age } \\
\text { (year) }\end{array}$ & $\begin{array}{c}\text { Education } \\
\text { level }\end{array}$ & Job & $\begin{array}{l}\text { Child's age } \\
\text { (month) }\end{array}$ & $\begin{array}{l}\text { Child's } \\
\text { gender }\end{array}$ \\
\hline \multirow{16}{*}{$\begin{array}{r}\text { Type } 1 \\
(n=16)\end{array}$} & Eigen values: 11.92 & 12 & 0.72 & 32 & University & Office worker & 23 & M \\
\hline & Variance: 23.8 & 18 & 0.68 & 40 & University & Office worker & 18 & $\mathrm{~F}$ \\
\hline & Cumulative: 0.24 & 20 & 0.83 & 32 & University & Office worker & 23 & $\mathrm{M}$ \\
\hline & & 24 & 1.06 & 42 & University & Office worker & 29 & $\mathrm{~F}$ \\
\hline & & 25 & 1.73 & 40 & Postgraduate & School staff & 30 & $\mathrm{M}$ \\
\hline & & 26 & 2.87 & 36 & University & School staff & 2 & $\mathrm{~F}$ \\
\hline & & 27 & 2.86 & 42 & Postgraduate & Office worker & 36 & $\mathrm{M}$ \\
\hline & & 28 & 3.34 & 45 & University & Office worker & 32 & M \\
\hline & & 29 & 0.79 & 38 & University & School staff & 24 & $\mathrm{M}$ \\
\hline & & 30 & 1.22 & 43 & University & School staff & 4 & $\mathrm{~F}$ \\
\hline & & 31 & 0.29 & 46 & University & Teacher & 8 & $\mathrm{M}$ \\
\hline & & 32 & 1.47 & 42 & Postgraduate & School staff & 16 & M \\
\hline & & 34 & 0.94 & 42 & University & Teacher & 30 & $\mathrm{~F}$ \\
\hline & & 38 & 0.77 & 42 & Postgraduate & Professor & 4 & $\mathrm{M}$ \\
\hline & & 39 & 0.73 & 42 & Postgraduate & Professor & 5 & $\mathrm{~F}$ \\
\hline & & 41 & 0.37 & 38 & Postgraduate & Researcher & 15 & $\mathrm{M}$ \\
\hline \multirow{15}{*}{$\begin{array}{l}\text { Type } 2 \\
(n=15)\end{array}$} & Eigen values: 6.57 & 1 & 2.03 & 37 & University & Office worker & 8 & M \\
\hline & Variance: 13.1 & 3 & 0.47 & 41 & University & Office worker & 10 & $\mathrm{~F}$ \\
\hline & Cumulative: 0.37 & 4 & 0.89 & 39 & University & Office worker & 17 & $\mathrm{M}$ \\
\hline & & 6 & 0.97 & 35 & University & School staff & 2 & M \\
\hline & & 7 & 0.58 & 43 & University & Office worker & 16 & M \\
\hline & & 9 & 0.71 & 33 & University & Office worker & 3 & $\mathrm{~F}$ \\
\hline & & 10 & 0.64 & 45 & Postgraduate & Professor & 18 & $\mathrm{~F}$ \\
\hline & & 11 & 0.74 & 40 & Postgraduate & Researcher & 25 & M \\
\hline & & 23 & 0.71 & 35 & Postgraduate & School staff & 6 & $\mathrm{~F}$ \\
\hline & & 37 & 0.67 & 41 & Postgraduate & Professor & 15 & M \\
\hline & & 42 & 0.27 & 33 & Postgraduate & Researcher & 11 & $\mathrm{M}$ \\
\hline & & 43 & 1.20 & 32 & University & Self-employed & 12 & M \\
\hline & & 44 & 0.29 & 33 & University & Office worker & 11 & M \\
\hline & & 45 & 0.99 & 30 & University & Office worker & 24 & $\mathrm{M}$ \\
\hline & & 46 & 0.90 & 37 & University & Self-employed & 4 & M \\
\hline \multirow{11}{*}{$\begin{array}{l}\text { Type } 3 \\
(\mathrm{n}=11)\end{array}$} & Eigen values: 2.56 & 2 & 0.46 & 38 & University & Office worker & 9 & M \\
\hline & Variance: 5.1 & 5 & 0.63 & 49 & Postgraduate & Office worker & 20 & $\mathrm{M}$ \\
\hline & Cumulative: 0.42 & 8 & 0.55 & 37 & Postgraduate & Nurse & 2 & $\mathrm{~F}$ \\
\hline & & 13 & 2.93 & 28 & University & Office worker & 36 & $\mathrm{~F}$ \\
\hline & & 21 & 1.64 & 28 & University & Teacher & 36 & $\mathrm{~F}$ \\
\hline & & 36 & 0.62 & 42 & University & Office worker & 30 & $\mathrm{~F}$ \\
\hline & & 40 & 0.45 & 43 & University & Self-employed & 26 & $\mathrm{~F}$ \\
\hline & & 47 & 0.79 & 39 & University & Office worker & 25 & $\mathrm{M}$ \\
\hline & & 48 & 0.26 & 36 & University & Office worker & 32 & M \\
\hline & & 49 & 0.43 & 33 & University & Office worker & 24 & $\mathrm{~F}$ \\
\hline & & 50 & 0.95 & 30 & Postgraduate & Office worker & 25 & M \\
\hline \multirow{8}{*}{$\begin{array}{c}\text { Type } 4 \\
(n=8)\end{array}$} & Eigen values: 2.43 & 14 & 0.72 & 35 & University & Office worker & 36 & M \\
\hline & Variance: 4.9 & 15 & 1.01 & 47 & University & Self-employed & 4 & $\mathrm{~F}$ \\
\hline & Cumulative: 0.47 & 16 & 0.65 & 37 & Postgraduate & Office worker & 9 & $\mathrm{~F}$ \\
\hline & & 17 & 0.86 & 41 & Postgraduate & Doctor & 3 & $\mathrm{~F}$ \\
\hline & & 19 & 1.13 & 47 & Postgraduate & Office worker & 14 & $\mathrm{~F}$ \\
\hline & & 22 & 0.65 & 35 & University & Nurse & 36 & M \\
\hline & & 33 & 0.53 & 38 & Postgraduate & School staff & 6 & M \\
\hline & & 35 & 0.61 & 42 & Postgraduate & Doctor & 5 & M \\
\hline
\end{tabular}

$\mathrm{P}=$ Population; $\mathrm{M}=$ Male; $\mathrm{F}=$ Female. 
Table 2. Correlation Matrix between Types

\begin{tabular}{lcccc}
\hline Variables & Type 1 & Type 2 & Type 3 & Type 4 \\
\hline Type 1 & 1 & & & \\
Type 2 & .17 & 1 & & \\
Type 3 & .36 & .43 & 1 & \\
Type 4 & .56 & .13 & .27 & 1 \\
\hline
\end{tabular}

strongly disagreed, to the extent that there was a difference of -2.00 or more between their standard scores and those of fathers belonging th type 3 , were "gaging in physical play together $(Z=-0.7)$ " and "helping children grow to be physically healthy $(Z=-0.2)$ ". Finally, the items with which this group strongly agreed to the extent that there was a difference of +1.00 or more between their standard scores and those of fathers belonging to type 4 , were "helping children to engage in religious activity $(Z=-0.7)$ " and "giving children stimuli appropriate to their developmental level $(Z=0.3)$ ". The items with which this group strongly disagreed, to the extent that there was a difference of -1.00 or more between their standard scores and those of fathers belonging to type 4 , were "guiding children in the right direction if anything is wrong $(Z=0.2)$ " and "helping children grow to be physically healthy $(Z=-0.2)$ ".

The findings presented about indicate that the fathers belonging type 1 took a democratic attitude toward parenting, as they sought to understand their children's minds, were quite tolerant, encouraged them to do what they wanted, and helped them to do so. They also respected their children's personal traits and assisted them in growing into full-fledged members of society. Thus, they placed the greatest emphasis on the character development of their children, and type 1 was therefore defined as being centered on character development.

\section{2) Type 2: Centered on social development}

Fifteen of the 50 fathers belonged to type 2 . Their average age was 36.9 years, and their children's average age was 12.1 months. Ten were university graduates and five had graduate degrees. Seven were office workers, and two were professionals. Two were school staff members, and two each were self-employed and researchers. Their children (eleven boys and four girls) were in good health. The items with which this type agreed the most were "helping children to solve problems on their own $(Z=2.5)$ " and "getting children to build the right values $(Z=2.2)$ ". In contrast, the items with which they disagreed the most were "understanding children's minds ( $\mathrm{Z}=$ -1.7)" and "taking care of children in a way that prevents disease $(Z=-1.4)$ ". The items with which the fathers belonging to type 2 strongly agreed, to the extent that there was a difference of +1.00 or more between their standard score and those of the fathers belonging to type 3 , were "getting children to build the right values $(Z=2.2)$ " and "helping children grow into full-fledged members of society $(Z=1.4)$ ". The items with which this group strongly disagreed, to the extent that there was a difference of -2.00 or more between their standard scores and those of the fathers belonging to type 3, were "understanding children's minds $(Z=-1.7)$ " and "being a role model by showing children how to behave $(Z=-0.9)$ ". The items with which this group strongly agreed, to the extent that there was a difference of +2.00 or more between their standard scores and those of fathers belonging to type 4 , were "giving children stimuli appropriate to their developmental level $(\mathrm{Z}=1.1)$ " and "helping children to engage in a religious activity $(Z=-0.2)$ ". The items with which this group strongly disagreed, to the extent that there was a difference of -2.00 or more between their standard scores and those of the fathers belonging to type 4 , were "giving frequent praise $(Z=-0.9)$ " and "understanding children's minds $(Z=-1.7)$ ".

Based on the findings presented above, it can be seen that the fathers belonging to type 2 attached more importance to social development than the fathers belonging to type 1 . They considered it important to help children to build the right values, to solve problems on their own and to become full-fledged members of society. Therefore, type 2 was defined as being centered on social development.

\section{3) Type 3: Centered on physical health and development}

Eleven of the 50 fathers belonged to this type. Their average age was 36.6 years, and their children's average age was 24.1 months. Eight were university graduates and three had graduate degrees. Eight were office workers, and one each was a nurse, teacher, and self-employed. Their children (five boys and six girls) were in good physical health. The items with which this type agreed the most was "helping children grow to be physically healthy $(Z=1.9)$ " and "engaging in physical play together $(Z=1.5)$ ". In contrast. the items with which they disagreed the most were "making up for mothers' shortcomings $(\mathrm{Z}=-1.7)$ " and "preserving familial authority $(\mathrm{Z}=-1.7)$ ". The items with which the fathers belonging to type 3 strongly agreed, to the extent that there was a difference of +2.00 or more between their standard scores and those of fathers belonging to type 4 , were "engaging in physical play together $(Z=1.5)$ " and "ensuring that children receive sufficient nourishment $(Z=1.3)$ ". The items with which the fathers in type 3 strongly disagreed, to the extent that there was a difference of -2.00 or more between their standard scores and those of the fathers in type 4, were "helping children do what they want $(Z=-1.6)$ " and "giving frequent praise $(Z=-1.1)$ ".

Based on the findings presented above, the fathers belonging to type 3 placed on emphasis on promoting physical 
Table 3. The Q-statements and Z-scores $( \pm 1.0)$ by the Parenting Types

\begin{tabular}{|c|c|c|}
\hline Type & Q-statement & Z-score \\
\hline Type 1 & $\begin{array}{l}\text { Q2. Getting children to build the right values } \\
\text { Q34. Helping children to build character } \\
\text { Q6. Helping children grow into full-fledged members of society } \\
\text { Q16. Giving lessons in manners } \\
\text { Q25. Facilitating social development } \\
\text { Q27. Understanding children's minds } \\
\text { Q31. Correcting behavior } \\
\text { Q17. Providing outdoor activities } \\
\text { Q22. Making up for mothers' shortcomings } \\
\text { Q23. Preserving familial authority } \\
\text { Q13. Offering language training } \\
\text { Q19. Helping children to maintain personal hygiene } \\
\text { Q26. Helping children acquire gender roles }\end{array}$ & $\begin{array}{r}2.1 \\
1.9 \\
1.7 \\
1.4 \\
1.3 \\
1.3 \\
-1.2 \\
-1.3 \\
-1.5 \\
-1.6 \\
-1.7 \\
-1.8 \\
-1.8\end{array}$ \\
\hline Type 2 & $\begin{array}{l}\text { Q1. Helping children to solve problems on their own } \\
\text { Q2. Getting children to build the right values } \\
\text { Q3. Helping children grow to be physically healthy } \\
\text { Q6. Helping children grow into full-fledged members of society } \\
\text { Q5. Giving children stimuli appropriate to their developmental level } \\
\text { Q4. Providing a safe environment } \\
\text { Q37. Satisfying children's intellectual needs } \\
\text { Q26. Helping children acquire gender roles } \\
\text { Q32. Teaching the importance of love } \\
\text { Q31. Correcting behavior } \\
\text { Q28. Taking care of children in a way that prevents disease } \\
\text { Q27. Understanding children's minds }\end{array}$ & $\begin{array}{r}2.5 \\
2.2 \\
1.9 \\
1.4 \\
1.1 \\
1.3 \\
-1.1 \\
-1.2 \\
-1.2 \\
-1.3 \\
-1.4 \\
-1.7\end{array}$ \\
\hline Type 3 & $\begin{array}{l}\text { Q3. Helping children grow to be physically healthy } \\
\text { Q8. Engaging in physical play together } \\
\text { Q9. Guiding children in the right direction if anything is wrong } \\
\text { Q11. Ensuring that children receive sufficient nourishmen } \\
\text { Q27. Understanding children's minds } \\
\text { Q35. Being a role model by showing children how to behave } \\
\text { Q12. Trying to promote health } \\
\text { Q16. Giving lessons in manners } \\
\text { Q26. Helping children acquire gender roles } \\
\text { Q29. Giving frequent praise } \\
\text { Q31. Correcting behavior } \\
\text { Q37. Satisfying children's intellectual needs } \\
\text { Q15. Helping children engage in religious activity } \\
\text { Q21. Teaching children to abide by the rules } \\
\text { Q30. Helping children to do what they want } \\
\text { Q22. Making up for mothers' shortcomings } \\
\text { Q23. Preserving familial authority }\end{array}$ & $\begin{array}{r}1.9 \\
1.5 \\
1.4 \\
1.3 \\
1.3 \\
1.3 \\
1.1 \\
1.0 \\
-1.0 \\
-1.1 \\
-1.1 \\
-1.4 \\
-1.6 \\
-1.6 \\
-1.6 \\
-1.7 \\
-1.7\end{array}$ \\
\hline Type 4 & $\begin{array}{l}\text { Q9. Guiding children in the right direction if anything is wrong } \\
\text { Q3. Helping children grow to be physically healthy } \\
\text { Q29. Giving frequent praise } \\
\text { Q30. Helping children to do what they want } \\
\text { Q2. Getting children to build the right values } \\
\text { Q18. Being a life mentor } \\
\text { Q22. Making up for mothers' shortcomings } \\
\text { Q5. Giving children stimuli appropriate to their developmental level } \\
\text { Q13. Offering language training } \\
\text { Q40. Providing safety education } \\
\text { Q19. Helping children to maintain personal hygiene } \\
\text { Q15. Helping children engage in religious activity }\end{array}$ & $\begin{array}{r}2.1 \\
1.6 \\
1.5 \\
1.3 \\
1.2 \\
1.0 \\
1.0 \\
-1.5 \\
-1.6 \\
-1.7 \\
-2.0 \\
-2.6\end{array}$ \\
\hline
\end{tabular}


health by providing enough nutrition and playing together physically, unlike the fathers belong to type 2 , who attached importance to social development. This implies that the fathers belonging to type 3 considered it advisable for children to grow to be healthy, and this type was therefore defined as being centered on physical health and development.

\section{4) Type 4: Centered on building values}

Eight of the 50 fathers belonged to this type. Their average age was 40.3 years, and the average age of their children was 14.1 months. Three were three university graduates and five had graduate degrees. Three were office workers, two were doctors, and one each was a nurse, school staff and selfemployed. Their children (four boys and four girls) were all healthy. The items with which this type agreed the most were "guiding children in the right direction if there's anything wrong $(Z=2.1)$ " and "helping children grow to be physically healthy $(Z=1.6)$ ". The items with which they disagreed the most were "helping children to engage in a religious activity $(\mathrm{Z}=-2.6)$ " and "helping children to maintain personal hygiene $(Z=-2.0)$ ".

Based on the finding presented above, fathers belonging to type 4 prioritized cultivating proper values and wanted to raise their children to be physically healthy. They placed an emphasis on guiding children in the right direction through discipline if they exhibit socially unacceptable behavior, and they also stressed the need to develop proper values and physical health.

\section{The Items Agreed or Disagreed Upon by Every Type}

As the findings presented above show, the fathers of young children were classified into four different paternal types that had distinctive characteristics. However, there were several statements with which fathers belonging to all types agreed or disagreed irrespective of their types, as shown in Table 4. The items that all types strongly agreed with were "giving lessons in manners $(Z=0.9)$ ", "fostering intimacy $(Z=0.4)$ " and "developing a parent-child bond $(Z=0.1)$ ". The item with which they disagreed the most was "providing a variety of experiences $(Z=-0.5)$ ", followed by "helping children to acquire gender roles $(Z=-1.2)$ ". Overall, the fathers wanted their children to feel a sense of intimacy with them and to be polite, and they intended to be devoted to their paternal roles to develop a bond with their children.

\section{DISCUSSION}

A general and universal behavior of parents is raising and teaching their children in a way that facilitates their growth
Table 4. Consensus Items and Average Z-scores

$(N=50)$

\begin{tabular}{llc}
\hline Q-statement & & Z-scores \\
\hline Q16 & Giving lessons in manners & 0.9 \\
Q7 & Fostering intimacy & 0.4 \\
Q36 & Developing a parent-child bond & 0.1 \\
Q33 & Providing a variety of experiences & -0.5 \\
Q26 & Helping children acquire gender roles & -1.2 \\
\hline
\end{tabular}

and development [1]. This study attempted to obtain information useful for providing parenting guidance investigating the subjective perceptions of 50 selected fathers of young children (2 36 months) about parenting, using the Q-methodology.

In the early childhood stage, parenting has been divided in four different types: affectionate-respecting, attentive-observant, caring-exemplary, and compassionate-encouraging [20]. In this study, the parenting behaviors of the fathers of young children were classified into four types, which respectively emphasized character development, social development, the promotion of physical health and development, and building values. This outcomes gunder scores the potential for parenting differences depending on whether the main nurturer is a father or a mother. In Yang's research [21], mothers performed the role of primary care-giver by satisfying the basic physiological needs of children, including a physical and emotional relationship, thereby reflecting needs in a child's daily life. Meanwhile, fathers exhibited high levels of interest in their children's cognitive development, achievement motivation, and academic achievement, rather their basic needs. Parenting was found to play a major role in improving social adjustment in children, establishing that fathers play role of behavioral models for their children [22]. In Capuozzo, Sheppard, and Uba's research [22], traditional approaches to parenting involved fathers playing a subsidiary role to mothers. As joint care-givers, fathers appeared to play a positive and active role involving a close emotional relationship in their children's everyday life. Therefore research should be conducted to compare maternal and paternal parenting behaviors by exploring the feelings, difficulties, and needs of fathers and mothers in detail.

Type 1 was centered on character development. The fathers belonging to this type were in their 40s and highly educated. They showed extensive interest in their children's character, which they thought was linked to personality development. They emphasized the importance of character development in the growth period, and also attached importance to family relations and interpersonal relationships in society. Regarding occupation, the largest proportion (six fathers), and they placed 
a greater emphasis on character development than any other type. The items with which this type agreed the most were "getting children to build the right values" and "helping children to build character". A study that examined the parenting awareness of fathers with young children found that they emphasized helping children to distinguish between right and wrong and building the right values [15], and their findings were similar to those of this study. Another study found that subjects considered it important to raise their children to become polite and courteous, and that they placed emphasis on character-building, which corresponds to the findings of this study [20]. In addition, another study found that setting limits on children's behavior in early childhood and making rules about behavior were considered important [23]. Their findings were similar to those of this study. In modern society, the importance of character development is accentuated, since each family only has a small number of children. Therefore, unconditional acceptance of children's behaviors and needs should be avoided; instead, diverse educational programs aimed at teaching parents to guide children's thought, judgment, and behavior in the right direction to assist their character-building should be provided.

Type 2 was centered on social development. The fathers belonging to this type had an average age of 36.9 years, and had various occupations. Their approach to parenting was influenced by their own interpersonal relationships and social experiences in their school years and at work. The items with which they agreed the most were "helping children to solve problems on their own" and "getting children to build the right values". They believed that the proper development of problem-solving skills and values would guarantee appropriate sociability. One study found that children could improve in prosociality and emotional regulation when their parents bolster their sociability during the growth period [24]. This was confirmed again in this study. According to Chang et al. [9], parenting is positively affected when fathers place an emphasis on sociability, and careful preparations for paternal involvement and the proper fulfillment thereof are required for that reason, which lends credibility to the findings of this study. Therefore, in order to have a better understanding of paternal behaviors in early childhood, it seems necessary to determine the relationship between satisfaction with work life and parenting.

Type 3 was centered on physical health and development. Eleven fathers belonged to this type, and their children's average age was 24.1 months. They were older than the children of the fathers of any other type, and their offspring were mostly in the early childhood stage. These fathers were highly interested in their children's physical health, as the rapid development of physical activities and the development of linguistic competence take place in early childhood [7]. The second most agreed-upon item was "engaging in physical play together". Dermott's study [25] established that children's growth and development are critically affected when their fathers make time to be with them, play with them in person, and engage in activities together in comparison to when fathers put their energy into doing something alone for their sake. Their findings lend credibility to those of this study. The most agreed-upon item in this group was "helping children grow to be physically healthy". A study found that in terms of paternal roles in infancy, subjects were especially aware of their role regarding physical health [26]. That finding coincides with those of this study. The most rapid growth and development occur in infancy. In this period, the required amount of nourishment increases in line with rapid growth and development, although children's digestive power is not yet sufficient, and this period also is characterized by improved motor skills and growing energy requirements that are attributed to active physical activities [26]. In this study, even fathers with infants paid attention to children's physical growth. A major concern about their health could be predicted. Accordingly, there will be a need to construct content focusing on ways to promote physical growth and development as part of developing parenting programs for fathers.

Type 4 was centered on building values. Eight fathers belonged to this type. Their average age was 40.3 years, and they were the oldest among the four groups. However, their children were 14.1 months old on average. Thus, they were raising their children in their later years, which results from the current tendency in Korea for the average age of marriage and the age for raising children to increase. The item with which fathers belonging to this type agreed the most was "guiding children in the right direction if anything is wrong". A study that examined the parenting of young fathers established that unlike past generations, fathers in modern times gave weight to their own mental roles as fathers owing to their economic stability [27], which is similar to the findings of this study. Another study that investigated fathers with children in early childhood found that fathers of infants considered it important for their children to maintain emotional stability and build values, which also corresponds with the findings of this study [28]. It has been reported that for children, building values is positively affected when the values of their fathers are well established and when they are on good terms with their fathers [29]. In essence, parenting is a process through which parents and children grow and become mature together. Fathers themselves should establish their own values first and live up to those values, since doing so exerts an influence on their children's values [1].

The items with which all the fathers agreed irrespective of 
their types were "giving lessons in manners", "fostering intimacy", and "developing a parent-child bond". This finding coincides with that of a study investigating mothers who cared for young children [7]. Regarding children's relationship with their parents, one study found that discipline for children was considered important, and another study found that intimacy was considered important in terms of affection, and that children's relationship with their parents also was regarded as important [30]. These findings lend credibility to the findings of this study. Parents tend to conceptualize parenting as being strictly divided into maternal and paternal roles. It is a reality that the importance of one's own role is recognized differently from that of another [27]. However, as confirmed in this study and in previous research, parenting is now judged to be similarly important by fathers, as a result of social changes. Hence, fathers should establish their own approach to parenting by seeking out opportunities to self-reflect on how they themselves were parented.

The item with which all fathers most strongly disagreed was "providing a variety of experiences". It has been found that fathers had little time to be with their children due to their hectic work schedules and requirements to stay out late, which had a negative impact on parenting [5]. The findings of this study are similar. All the subjects were employed, and they were not young fathers. Therefore, they thought that it was difficult for them to gain hands-on experience with their children. A previous study explained that children's self-esteem improves when their fathers provide them with various opportunities to learn together [29]. Based on this outcome, possibilities should be explored to help fathers devise plans for maximizing their parenting in light of recent changes in paternal roles.

In modern times, fathers are no longer mere parenting assistants. They are expected to perform the role of a householder, and they also are required to create "a new image of the father" by actively taking part in parenting, sharing household chores, interacting with children, and providing children with nurturing care. It is necessary to pay continuing attention to paternal parenting behaviors so that fathers in the 21st century can succeed both at the workplace and in their role as parents at home.

In this study, the perceptions of parenting were explored among fathers who were on paternity leave and took care of children for more than 8 hours a day. The research subjects were mostly drawn from double-income couples. It is known that spouses jointly share the physical and mental burden of child-rearing and mutually divide the child-care burden in a supportive way. Thus, fathers' participation in parenting shows a positive effect on marital relationships and childrearing, and parenting by fathers should be considered as in- dicative of a positive outcome.

The paternal parenting types identified in this study explained $47.0 \%$ of the total variance, which is relatively low. However, a strength of our study is that fathers' subjective perceptions on parenting were divided into four types, each with distinct characteristics, as well as some overlapping features. Shared opinions among fathers related to the importance of personality, sociality, physical health, and value formation. To popularize these results, expanded and repeated research is needed. Additionally, the P-samples of this study were fathers with children from 2 to 36 months of age. Therefore, a limitation is that fathers may have different perceptions of parenting across developmental stages. For this reason, a subsequent study should distinguish among developmental stages. Additionally, comparative studies should be conducted according to parenting experience.

\section{CONCLUSION}

As a result of analyzing the subjective perceptions of fathers with young children on parenting, four different types were identified. One was centered on character development. This type placed an emphasis on human nature, namely character. Another type was centered on social development. This type stressed the ability to interact smoothly with others and form positive relationships with various people. A third type was centered on physical health and development. This type emphasized avoiding diseases, not being weak, being active, and age-appropriate physical growth. The fourth type was centered on building values. This type placed an emphasis on fostering discernment and judgment to be successful in social life. The findings of this study provide information on paternal parenting in early childhood, and are expected to make a contribution to the development of educational and interventional programs tailored to the characteristics of the four different types of fathers with young children.

As only a small number of fathers, who were selected by convenience sampling and who had young children, were investigated to explore their subjective perceptions, the findings of this study might not be generalizable. In the future, additional research should be implemented with a wider variety of subjects. Furthermore, parenting programs geared toward fathers with young children should be developed and implemented, and their effects should be verified.

\section{Conflict of interest}

No existing or potential conflict of interest relevant to this article was reported. 


\section{REFERENCES}

1. Abidin RR. The determinants of parenting. Journal of Clinical Child Psychology. 1992;21(4):407-412. https://doi.org/10.1207/s15374424jccp2104_12

2. Park SJ, Kang KA. Development of a measurement instrument for parenting behavior of primary caregivers in early childhood. Journal of Korean Academy of Nursing. 2015;45(5):650-660.

https://doi.org/10.4040/jkan.2015.45.5.650

3. Riina EM, Feinberg ME. Involvement in child rearing and mothers' and fathers' adjustment. Family Relations. 2012;61(5):836-850. https://doi.org/10.1111/j.1741-3729.2012.00739.x

4. Day RD, Lamb ME. Conceptualizing and measuring father involvement. London: Lawrence Erlbaum Associates Publishers; 2003. p. $1-55$.

5. Flouri E, Buchanan A. The role of father involvement in children's later mental health. Journal of Adolescence. 2003;26(1):63-78. https://doi.org/10.1016/S0140-1971(02)00116-1

6. Majdandžić M, de Vente W, Colonnesi C, Bögels SM. Fathers' challenging parenting behavior predicts less subsequent anxiety symptoms in early childhood. Behaviour Research and Therapy. 2018; 109:18-28. https://doi.org/10.1016/j.brat.2018.07.007

7. Wilson KR, Prior MR. Father involvement and child well-being. Journal of Paediatrics and Child Health. 2011;47(7):405-407. https://doi.org/10.1111/j.1440-1754.2010.01770.x

8. Fagan J, Palm G. Fathers and early childhood programs. Canada: Thomson Delmar Learning; 2004. p. 1-100.

9. Chang LR, Chiu YN, Wu YY, Gau SS. Father's parenting and father-child relationship among children and adolescents with attention-deficit/hyperactivity disorder. Comprehensive Psychiatry. 2013;54(2):128-140.

https://doi.org/10.1016/j.comppsych.2012.07.008

10. Stock NM, Rumsey N. Parenting a child with a cleft: The father's perspective. The Cleft Palate- Craniofacial Journal. 2015;52(1):31-43. https://doi.org/10.1597/13-035

11. Grant CC, Duggan AK, Andrews JS, Serwint JR. The father's role during infancy. Factors that influence maternal expectations. Archives of Pediatrics and Adolescent Medicine. 1997;151(7):705-711.

12. Meuwissen AS, Carlson SM. Fathers matter: The role of father parenting in preschoolers' executive function development. Journal of Experimental Child Psychology. 2015;140:1-15.

https://doi.org/10.1016/j.jecp.2015.06.010

13. Ramchandani $P$, Iles J. Commentary: Getting fathers into parenting programmes- A reflection on Panter-Brick et al. (2014). The Journal of Child Psychology and Psychiatry. 2014;55(11):1213-1214. https://doi.org/10.1111/jcpp.12321

14. Sicouri G, Tully L, Collins D, Burn M, Sargeant K, Frick P, et al. Toward father-friendly parenting interventions: A qualitative study. The Austalian and New Zealand Journal of Family Therapy. 2018; 39(2):218-231. https://doi.org/10.1002/anzf.1307
15. Wilson S, Durbin CE. Effects of paternal depression on fathers' parenting behaviors: A meta-analytic review. Clinical Psychology Review. 2000;30(2):167-180. https://doi.org/10.1016/j.cpr.2009.10.007

16. John A, Halliburton AL. Q methodology to assess child-father attachment. Early Child Development and Care. 2010;180(1-2):71-85. https://doi.org/10.1080/03004430903414711

17. Zabala A, Sandbrook C, Mukherjee N. When and how to use Q methodology to understand perspectives in conservation research. Conservation Biology. 2018;32(5):1185-1194. https://doi.org/10.1111/cobi.13123

18. McKeown B, Thomas DB. Q methodology. 2nd ed. United States of America: SAGE Publications Inc.; 2013. p. 17-64.

19. Dennis KE. Q methodology: Relevance and application to nursing research. Advances in Nursing Science. 1986;8(3):6-17.

20. Park SJ, Kang KA, Kim SJ. Types of child rearing behavior of parents during early childhood: Q-methodological approach. Journal of Korean Academy of Nursing. 2013;43(4):486-496. https://doi.org/10.4040/jkan.2013.43.4.486

21. Yang S. Men's fathering experiences focused on tensions and conflict of multiple roles. Journal of Digital Convergence. 2013;11(2): 375-383.

22. Capuozzo RM, Sheppard BS, Uba G. Boot camp for new dads: The importance of infant-father attachment. Young Children. 2010;65 (3):24-28.

23. Park J, Rhee U. Children's peer competence: Relationships to maternal parenting goals, parenting behaviors, and management strategies. Korean Journal of Child Studies. 2001;22(4):1-15.

24. Chae YM. Young children's emotion control and social ability according to parenting attitude. Journal of Young Child Studies. 2010;13:117-132.

25. Dermott E. Intimate fatherhood: A sociological analysis. London: Routledge; 2008. p. 5-45.

26. Kim NH. Early childhood parents' perceptions of good father's roles and social roles for good fathering. Journal of Future Early Childhood Education. 2011;18(2):79-98.

27. Giallo R, D'Esposito F, Christensen D, Mensah F, Cooklin A, Wade C, et al. Father mental health during the early parenting period: Results of an Australian population based longitudinal study. Social Psychiatry and Psychiatric Epidemiology. 2012;47(12):1907-1916. https://doi.org/10.1007/s00127-012-0510-0

28. Cho HS, Kim JH, Kim TI. Images of father pursued by the fathers of young children. Early Childhood Education Research and Review. 2008;12(1):239-264.

29. Lamb ME, Sagi A. Fatherhood and family policy. 1st ed. New Jersey: Lawrence Eribaum Associates; 2014. p. 15-70.

30. Menashe A, Atzaba-Poria N. Parent-child interaction: Does parental language matter? British Journal of Developmental Psychology. 2016;34(4):518-537. https://doi.org/10.1111/bjdp.12147 